droplets in which, so far as is known, secretory products do not appear.

${ }^{1}$ Wolman, M., Proc. Soc. Exp. Biol. Med., 75, 583 (1950).

${ }^{2}$ Belt, W. D., and Hayes, E. R., Stain T'ech., 31, 117 (1956).

${ }^{3}$ Chou, J. T. X., Quart. J, Micro. Sci., 98, 59 (1957).

+ Oettlé, A. G., J. Roy. Micro. Soc., 70, 255 (1950).

"Chou, J. T. Y., and Bradbury, S., Nature, 179, 1245 (1957).

'Altmann, R., Arch. Anut. Physiol., Anat. Abt., Supp.-Band, 86 $(1889)$.

7 Altmamn, R., "Die Elementarorganismen und ihre Bezichungen $\%$ den Zellen", ind edit. (Veit, Leipzig, 1894).

- Starke, J., Arch. Anal. Physiol., Physiol. Abt. (no vol. number), 70 $(1895)$

"('ain, A. J., Biol. Rev., 25, 73 (1950). \author{
Fischer, A., "Fixierung, Färbung und Bau des Protoplasmas"
(Fischer, Jena, 1899). \\ 11 Roque, A. L., J. Roy. Micro. Soc., 74, 188 (1954). \\ ${ }^{12}$ Shafiq, S. A., Quart. J. Miero. Sci., 94, 319 (1953). \\ ${ }^{13}$ Ross, K. F. A., and Chou, J. T. Y., Quart. J. Micro. Sci. (in the \\ press). \\ 14 Schmidt, W. J., Nova Acta Leop., 7, 1 (1939). \\ ${ }^{1.5}$ Buams, H. W., Tahmisian, T. N., Devine, R. L., and Anderson, E. \\ J. Biophys. Biochem. Cytol., 2 (Stupp.), 123 (1956). Clayton, B.-P.' \\ Jautseh, K., and Jordan-Luke, B. M., Quart. I. Miero. Sci. (in \\ the press) \\ 18 Geren, B. B., and Schmidt, F. O., J. App. Phys., 24, 1421 (1953). \\ 17 Hirsch, G. (.., "Form- und Stoffwechsel der Golgi-Körper" (Born- \\ traeger, Berlin. 1939). \\ ${ }_{28}$ Worley, L. G., and Worley, E. K., J. Morph., 73, 365 (1943)
}

\title{
NUTRITION OF THE VERY YOUNG
}

$\mathrm{T}$ HE 111th meeting of the Nutrition Society (which was also the 50th meeting of the Scottish Group), held in Queen's College, Dundee, on September 21, took the form of a symposium on "The Nutrition of the Very Young". The chairman was Prof. J. L. Henderson (Department of Child Health, Queen's College, Dundee).

In the first paper, on "Nutrition in the Neonatal Period", Dr. C. A. Smith (Boston Lying-in Hospital, Boston, Massachusetts) pointed out that the nutritional status of newborn infants from apparently well-fed mothers can vary appreciably. There would appear to be little proof of a constant association between maternal and foetal nutrition. It may be that, with the relatively slow growth of the human footus when compared with some animals, all nutritional requirements can be met by a maternal diet which is marginal or sometimes sub-marginal. This being so, the variations in foetal weight so commonly observed may arise from factors other than maternal diet or stores. Abnormalities in weight and morphology of the placenta have been shown to give rise to a considerable degree of fœetal under-nutrition, and infants thus retarded show rapid growth once dietary energy is available after birth. The nutritional status of the foetus is therefore a product, not only of maternal nutrition, but perhaps also of uterine and placental factors which cannot all be readily inspected at delivery.

In regard to the diet of the newborn infant, Dr. Smith considered that natural feeding of infants was probably not the eustomary method in his part of the United States. Indeed, one school of thought in that country has brought spoon-feeding of somisolid foods to the second and even the first week after birth, but considerable care must be taken to ensure that correct amounts and proportions of nutrients are supplied.

Premature infants in the Boston Lying-in Hospital are bottle-fed from a human milk bank for one or two months, but this is a rare eventuality in the United States, where in many nurseries for premature infants an artificial mixture of modified cow's milk is fed from birth. The reason for preferring human to cow's milk is its reliable digestibility and the reduced osmolar load of its electrolytes for renal excretion. Dr. Smith pointed out that the greater nitrogen retentions and gains in weight made by infants on artificial foods require evaluation by long-term rather than by short-term work which might be misleading. Recent work in Chicago showed that the large and prompt gains frequently observed after introduction of artificial feeding were often associated with overretention of sodium, chloride and water. After renal adjustment to the increased electrolyte content of the diet, a return to isocaloric feeding of human milk resulted in a temporary loss of weight and negative sodium and chloride balance. There is a danger in artificial feeding that 'supermineralization' may be forced on the growing infant. Dr. Smith has not boen giving supplements of iron to torm infants in his care for a few weeks after birth, because most of them will be receiving iron in cereal foods at throe months, and experiments have shown that it is not until around that time that iron begins to be absorbed from the infant food.

Vitamin supplements given now are less than those given 15-20 years ago. Daily dosage of a concentrate containing $50 \mathrm{mgm}$. of ascorbic acid, 1,000 uniss of vitamin $D$ and 5,000 units of vitamin $A$ is begun lite in the szcond or third week.

Dr. F. E. Hytten (Obstetric Medicine Research Unit, Medical Research Council, Foresterhill, Aberdeən) read the second papər, entitled "Some Theoretical and Practical Difficulties in Neonatal Feeding".

During the latter half of the nineteenth century and up to the First World War, propaganda for breast feeding was undoubtedly justified because of the poor quality of human-milk substitutes and the poor conditions of hygiene prevailing; but it is doubtful whether such emphasis noed now be laid on breast feeding, especially in view of the many household responsibilities which the modern mother has to bear during lactation. The fact that the fall in infant mortality and in breast-feeding rate since 1929 has been closely parallel at least indicates that there is no longor the same need to appeal for breast feeding if it is a burden to the mother.

The most common complaint of the breast-feeding mother is general fatigue. This is understandable in view of the extra work entailed in caring for and feeding the baby, especially over the first few weeks when she can expect no more than four hours continuous sleep. Fatigue is most noticeable among women without domestic help. Those mothers living with relatives who could relieve them of household duties while they were feeding the baby were less affected by reason of lower energy expenditure. Fatigue is accentuated by worry, and worry is more characteristic of mothers who are breast feeding. Many breast. fed babios cry excessively, even when gaining woight satisfactorily and thriving in other respects, and it is difficult to convince the mother that hunger is not the causs. A change to bottle feoding is often desirable in such a case and this in itself often stops the crying.

Under modern conditions of living, if the mother is having difficulty with breast feeding or is unwilling to maintain it through dissipation of hor available 
energy in household tasks, it is more practical and better for both her physical and mental health to encourage her to feed the baby by bottle.

In his paper entitled "The Nutrition of Young Animals", Dr. T. R. Preston (Rowett Research Institute, Aberdeen) considered problems encountered in rearing calves and pigs, the only mammals commonly reared both artificially and naturally.

Young pigs are normally allowed to suckle for eight weeks with supplementary ad lib. feeding of a dry meal from about the fourth week. However, by rearing from soon after birth on a synthetic diet, an extra litter of pigs can be produced every two years from each sow.

Because of the economic value of cow's milk for human consumption, only pedigree calves are normally suckled. The majority of calves are reared artificially soon after birth on varying amounts of cow's milk or milk substitute.

The successful rearing of pigs without colostrum is almost impossible, because the pig, unlike the human, relies on colostral transfer of immunity, the placenta being impervious to antibodies. Piglets are therefore allowed to suckle for a few days before feeding artificially. Growth and mortality have been variable on artificial feeding from two days of age and as much as 61 per cent mortality has been recorded between three days and eight weeks. The system of feeding artificially from the third day has therefore only found limited application.

Weaning at ten days has met with most success in practice. A dry meal mixture based on dried skimmed milk powder with added starch, glucose, suerose, fishmeal, minerals, vitamins and antibiotics is fed with water supplied separately. Weaned in this way the pig eats very little at first, but after a preliminary check period of 3-15 days food and water are consumed in increasing amounts, and growth is rapid, so that at eight weeks artificially reared pigs are often as heavy or heavier than pigs reared naturally.

The more successful rearing from ten days of age is associated with the development, during the first week after birth, of enzyme systems capable of digesting dietary starch and sucrose.

Like the young pig, the calf depends on colostrum for immunity from infectious diseases, and this is supplied by allowing it to suckle for three days or by feeding colostrum from a bucket. It is then usual to feed whole milk or a reconstituted synthetic or semi-synthetic milk for 8-12 weeks before weaning on to dry meal and roughage. Mortality is around 8 per cent.

Up to about four weeks of age lactose and glucose are the most suitable carbohydrates for synthetic milk diets because during early life the enzyme systems for splitting starch and sucrose are just developing.

The sooner the calf becomes a functional ruminant the more cheaply it can be reared. The major stimulus to rumen development is ingestion of solid food, and rumination in calves given early access to solid food begins when they are two to three weeks of age. It has been shown recently that calves made adequate growth when fed from three weeks of age on a simple dry meal mixture with hay and water.

Speaking on "Idiopathic Hypercalcæmia of Infants", Dr. R. G. Mitchell (Department of Child Health, University of St. Andrews) pointed out that, in eighteen cases studied during four years, the age of onset of the illness ranged from the third to the ninth month. Symptoms were anorexia, loss of weight, vomiting, constipation and a plasma calcium-level greater than $12 \mathrm{mgm} . / 100 \mathrm{ml}$. In eleven cases the blood urealevel was greater than $50 \mathrm{mgm} . / 100 \mathrm{ml}$. The clinical features and high rato of calcium absorption from the intestine suggested a vitamin $\mathrm{D}$ effect. Investigation showed that intakes of vitamin $\mathrm{D}$ were greater than 1,000 I.U. daily, with eleven cases taking more than 2,000 I.U. daily. Intakes of the latter order have been shown to interfero with child growth but are much less than intakes reported for vitamin D poisoning. Although tho children affected may have a lower requirement than normal for vitamin $D$, it is possible that there may be factors which enhance vitamin $\mathrm{D}$ activity. However, neither sunshine, deficiency of essential fatty acids, abnormal constitu. ents of cod liver oil nor administration of alkali as milk of magnesia were found to be likely causes. It was noted that in about a third of the cases a history of infection was associated with the illness and in seventeen of the eighteen cases dried cow's milk fortified with ergocalciferol was fed. Thus calcium intake would be high and a major part of the ergocalciferol would be given in milk, a circumstance which has been shown to enhance activity of the vitamin.

Most infants recover spontaneously if given a diet low in calcium without added vitamin D. Autopsy on three who died showed extensive nephrocalcinosis. The twelve surviving children, whose cases were followed up, have apparently made a complete recovery although still below average height and weight.

The final paper on "Hypercalcæmia in Infants and Young Animals" was read by Dr. A. M. MacDonald (Royal Hospital for Sick Children, Glasgow), who discussed certain aspects of renal pathology in infants and in young animals. The severe form of kidney lesion invariably shows stainable calcium deposits, but with it a destructive granulomatous type of lesion is found often lacking in stainable calcium. Stainable calcium deposits are not therefore considered essential in identifying early stages of the disease.

In both mild and severe form the lesion can be found in infants dying of a wide range of diseases such as hypophosphatasia, gastro-enteritis and constipation. The ages of children showing this lesion vary from four to eighteen months with a peak at nine months. It is suggested that where similar lesions are found by chance there is likely to be an association with hypercalcæmia, excessive vitamin $D$ intake or a metabolic defect involving vitamin $D$.

To follow the evolution of the kidney lesion, calves, rabbits, guinea pigs, rats and mice were given exceptionally large doses of vitamin D and killed serially.

It is known that vitamin $\mathrm{D}_{3}$ was present in virtually all infant foods in daily doses of $3,000-4,000$ I.U. These amounts are well above the dose of $700 \mathrm{I} . \mathrm{J} . / \mathrm{day}$ accepted as adequate for prevention of rickets.

The number of infants dying from widely different eauses and showing this renal lesion suggests that hypercalcæmia in infants might be common owing to vitamin $\mathrm{D}$ additives in food.

It is expected that the papers presented at the meeting will be published in extenso in the Proceedings of the Nutrition Society, Vol. 17, No. 1, early next year. J. DAvIDSON 